\title{
Taobao Anchors Strategically Promote Impulsive Buying of Consumer
}

\begin{abstract}
Yunying Zhang*
Cheshire Academy

*Corresponding author. Email: yunying.zhang@cheshireacademy.org

ABSTRACT

Live- stream shopping is the next big thing to enter the world of e-commerce, not only in China, but also in the whole world. Platforms in Europe and America, such as Facebook and Amazon have already implemented livestream shooting into their branding. In the future, the growth of live streaming e-commerce may thoroughly revolutionize consumers' spending habits and the entire consumer market. In the development of live streaming E-commence, the question of how live streaming anchors enhance sustainable marking effects using customer phycological strategy is currently a major topic in the live streaming marketing sector. Accordingly, based on the theory of impulse buying, this study direct examines the application of the theory of guided consumption, decoy effect, time-limited offer, anchoring effect and the effect of authority in Live Streaming platform, using the anchors in Taobao Live as the subject of study to see how the anchors apply those strategies in their daily live streaming and subconsciously influence consumers to make impulse purchases.
\end{abstract}

Keywords: Taobao Live, Live Stream E-commerce, Impulse purchase, Sale Strategy, Livestreaming Economy

\section{INTRODUCTION}

In recent years, with the rapid development of Internet and mobile payments, $\mathrm{C} 2 \mathrm{C}$ system (Customer to Customer) had shown explosive growth around the world. In China, online shopping has seen explosive growth. As of 2020, over 700 million Chinese are expected to shop online compared to only 600 million in 2018, partially due to COVID lockdown propelled it further. In 2020, Chinese e-commerce is projected to be 41 trillion dollars [1]. With the development of online shopping in China, the livestreaming e-commerce, promoting and selling goods through influencer streams on media channels, also grow swiftly. The size of the of live e-commerce market continues to expand from 2017 and 2020. The scale and utilization rate of mobile online shopping users. As of December 2020, the number of mobile online shopping used has reached seven hundred million. According to CNNIC report data, as of December 2020, the number of live webcast users in China has reaches 617 million. Among them, the number of e-commerce live broadcast is 388 million [2]. Yet, with the explosive growth of livestreaming ecommerce, its viciousness exposed to people. The new shopping way has boosted consumer' $\mathrm{s}$ impulse spending because of anchor strategically promotion. This article will further discuss how customer psychological strategies have applied into the live streaming platform, using the anchors in Taobao Live, the most mainstream business broadcast platform for livestreaming E-commerce, as real cases. In the article, the author participates in the online chats on the Taobao live in order to understand the interaction between the live streamer and the audience and combine practical with consumer psychology knowledge to discover the question.

\section{ONLINE SHOPPING IN CHINA}

Since 2013, China had become the world' s largest online retail market for eight consecutive years [2]. According to the 47th Statistical Report on Internet Development in China issued by CNNIC, from 2015 to 2020, in five years, China' s online retail sales exceed 10 trillion yuan, with a compound annual growth rate of $24.6 \%$ [2]. Also, the report showed that livestream shopping had become a popular shopping method among internet users, with $66.2 \%$ of internet users purchasing livestreaming products [2]. Taobao, the subordinate online shopping application of Alibaba 
company, is the biggest and most well-known $\mathrm{C} 2 \mathrm{C}$ platform in China. Its live broadcasting platform, Taobao Live, has the lion' s share of live streaming at around $80 \%$ in Chinese market [1]. Unlike traditional live streaming platforms, Taobao Live uses features that anchors can live broadcast with the audience in realtime to carry out product marketing. The anchor in Taobao live is more like a salesman. They demonstrate and critique the products, explain features and sporadically answer the audience' s call-in questions. To encourage the audience to order, anchors send coupons or discounts to customers and urge viewers on with calls to action like "just buy it" and "grab it now". So far, the strategy works very well. An increasing number of people watch live stream and place orders in the live broadcasts because of anchor' $\mathrm{s}$ coupons and discounts. With the gradual maturity of livestreaming E-commerce and increasing benefits, more celebrities begin to participate in the network broadcast or cooperate with famous anchors to live broadcast and sell products. The cooperation between anchors and celebrities increases exposure of products to both-sides fans, in doing so, leads to net new product sales. In 2019 November 6th, Kim Kardashian joined Taobao Live and collaborates with the anchor Viya, who is the number one anchor in Taobao Live with 9.64 million followers, to promote her brand's new perfume, KKW. At the start of the live stream, she already sold out 150,000 bottles of the perfume in a matter of seconds [3]. The corporation between celebrities and influential live streamer attracts more network traffic to the product, making products more exposure to the customer.

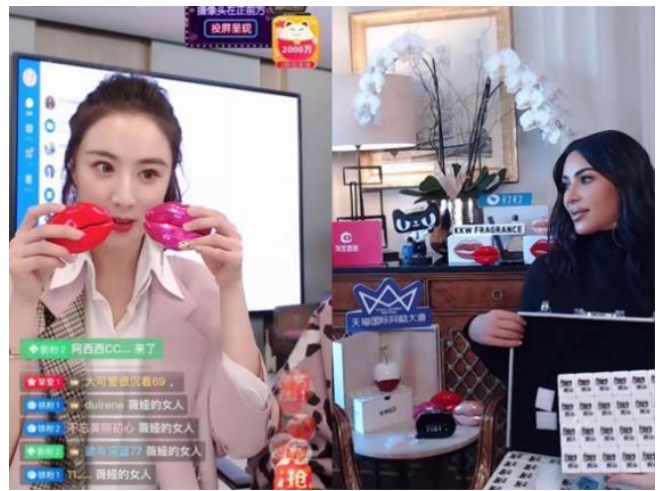

Figure 1. Kim Kardashian in Viya live to promote her new collection

\section{IMPULSE PURCHASE}

An impulse purchase is an unplanned decision to buy a product or service made just before a purchase [4]. It is usually triggered by emotions and feelings for a customer to take such buying decisions at the spur of the moment. The essence of impulse purchase is the release of dopamine. Dopamine is the brain's reward pathway. When people do things that feel good to them, it will lead to the release of dopamine which makes people happy and satisfied [5].

According to Sid Hawkins Stern's articles, The Significance of Impulse Buying Today, he describes four different types of impulse purchase----Pure Impulse Buying, Reminder Impulse Buying, Suggesting Impulse Buying, and Planned Impulse Buying [6]. Pure Impulse Buying is where the consumer breaks their normal pattern of consumption. Reminder Impulse Buying is when the consumer forgets to add an item into their shopping list, he sees the product again and that makes him to place an order. The next is Suggesting Impulse Buying, which consumers first see an interested product and convince themselves that they need the item. The final type of impulse buying is Planned Impulse Buying, which describes when consumer enter a store thinking about certain item but are waiting for a deal to induce them to makes a purchase. In live streaming, the anchors strategically use consumer psychology to promote the impulse buying of consumers.

\section{STRATEGICALLY PROMOTE IMPULSIVE BUYING OF CONSUMER}

\subsection{Guided Consumption}

Taobao Live used a model of "consumer-active shopping + anchor-guided shopping". Consumer-active shopping is costumer's purposeful consumption. Consumers go to Taobao because they need to buy certain products, while during their process of shopping, they may click a recommended link of live streaming. In the studio, the anchor is introducing the product. It could be shampoo, makeup, or a piece of clothing that is not consumers desperately needed right now, but by recommending and explaining, Taobao anchors make consumers generate purchase idea, which contributes to their suggesting impulse buying.

\subsection{Decoy Effect}

Decoy Effect is a theory that talks about when people choose between two comparable options---target and competitor, a third new option---the decoy or the lure---appears and makes the price of the target much more attractive and acceptable [8]. The decoy(lure) is not intended to sell, but to nudge consumer away from the "competitor" and towards the "targets" [8]. To further understand how decoy effect apply in the lives streaming, people need set up a scene in real life. Buying cleansing mask in an anchor's broadcast, the anchor may give the costumer several packages. The first and second packages don't look like a good deal, but the third one is very modest and cost-effective. By contrast, people will choose the third one. The decoy effect gives consumers the appearance of making the 
most cost-effective decision, making it easier to convince themselves to place order.

\subsection{Time-Limited Offers}

Time Limited offers is when customer purchase over a period of time, they can receive any type of deal, discount or promotion [9]. This is based on economic theory in which a limited supply of a good but with a high demand for that good will result in a mismatch between the desired supply and demand equilibrium [10]. Shortage will stimulate people to strive for it. Things like diamond, gems and gold which are all very difficult for normal to obtain and this is why they have very high value. Also, when something that is easily available becomes more and more difficult, people lose part of the freedom of choice. There is a vested interest in human beings, and the possibility of not being free creates a strong resistance and leads people to do something to avoid losing it. Applying the strategy to live streaming, in the live broadcast, the anchors will first tell consumer that there are only a few goods, but a lot of customers who want to buy. Therefore, if the customers do not want to miss the chance, place order as soon as possible. Also, while the customer is still hesitating whether to buy or not, anchors tell there is time-limited discount. If customers place order right now, they also get coupons or gifts. Thus, in order not to lose benefits, a lot of people will not control the order to buy.

\subsection{Anchoring Effect}

Similar to decoy effect, Anchoring effect also creates an illusion of consumption to consumers. The anchoring effect is a cognitive bias that descried the common human tendency to rely too heavily on first information of a things [11]. Once the value of this anchor is set, all future negotiation and decision are based on the relation to the anchor. This bias occurs when interpreting future information using this anchor to gauge. Applying the anchoring effect in live streaming, the words "anchor" points to the first impression of the price. Normally, price itself is depends on the balance of supply and give. But if the business use anchoring effect, it reverses the potions of the need and prices. Consumers' intention is manipulated by the price. A product in live broadcasts usually has two prices, the current price and the erased original price. The original price is the "anchor". Comparing the original and current price, customer will find the price has been reduced a lot. So, it makes consumer feel a good deal to buy the product at the current price. In livestreaming broadcast, the anchors may contact the merchants to let them set original price a little higher. Then when they are in live streaming and sells with current price that less than the original price, consumer will feel it is acceptable for them to buy a price less than original price. For example, the actual price of a jacket is 499 yuan, but it can be marked as 700 yuan as original price. This 700 is an anchor price, which improves the user's perception of the value of this product---this product is of good quality and was worth 700 yuan now 499 yuan. Hence, customer will feel happy that they took advantage of the low price and is willing to place order.

\subsection{The Effect of Authority}

The suggestion effect of authority refers to the fact that if a person as a Key Opinion Leaders, who has a high status, authority and respect from acquaintances, his recommendation and option can easily attract attention of others and is listened among the public [12]. For example, when a famous web celebrity recommends a product, his or her fans are willing to buy it because of their sense of authority as KOL (Key Opinion Leaders). In the live streaming, anchors are playing the role of KOL. For instance, Austin Li is a very famous anchors in China who sells beauty makeup in his broadcasting room. In the eyes of consumers, once the product is recommended by him, the quality must be guaranteed, because he is very strict about the control of products. People don't need to worry about the quality of products when they buy products from him. And Austin Li's recommendation is also a direct indicator of popular products. So, consumer especially female consumer will be very assured to buy the product in his live streaming. For female customer, Austin Li is known as "Woman's Friend", because the products he recommends are always very popular and fashionable. So female consumer very believes to Austin's words and willing to buy products he recommends. In live streaming field, all anchors want to be KOLs, because if they do, anything they recommend will become hot style.

In addition, the corporation of the celebrities and anchors is another example of the effect of authority. This time the celebrity play KOL role. Because the fans of the celebrities trust their icons, they believe the products selected by celebrities are guaranteed and are not defective, and thus they are willing to place order. Also, some celebrities are fashion icons. All clothes they recommend, or wear become hot styles. Their big effect of authority makes the products as long as their recommended, fans will be sure to order.

\subsection{Sunk Costs}

The sunk cost is an irretrievable cost, which cannot be recovered once it spent [13]. In live streaming, the anchor will open pre-sale and ask the consumer to delivery of the deposit. The deposit is just a little money, but when the costumer who already paid the deposit, does not want the product, he cannot be 
refunded the deposit. It seems like the person lost a lot of money. Therefore, when people do not want the item but already paid a deposit for, they may still continue buying. The sunk cost effect promotes the impulse buying because the small number of deposits give consumers the illusion that the item is not so expensive, so they click to order. But when they regret it later, they cannot give up their deposit, the sunk cost, and thus they spend much more money to a product that they do not like.

\section{CONCLUSION}

This article insight into the full sense of the application of customer psychological strategies on live streaming platform like Taobao. With the further discuss of the theory of guided consumption, decoy effect, time-limited offer, anchoring effect and the effect of authority in Live Streaming platform, audience may have a sense of the marketing strategies of live streaming anchors and notice how themselves make impulse purchases under the subliminal guidance of the anchor. This study can effectively guide the practice of consumer's buying behavior in live streaming scenes and for consumer it makes them reduce subconscious impulse spending.

\section{ACKNOWLEDGMENT}

First and foremost, I would like to show my deepest gratitude to my teachers and professors in my school, who have provided me with valuable guidance in every stage of the writing of this thesis. Further, I would like to thank all my friends and roommates for their encouragement and support. Without all their enlightening instruction and impressive kindness, I could not have completed my thesis.

\section{REFERENCES}

[1] Greenwald, Michelle. "Live Streaming E-Commerce Is The Rage In China. Is The U.S. Next?" Forbes, 11 Dec. 2020, www.forbes.com/sites/michellegreenwald/2020/12 /10/live-streaming-e-commerce-is-the-rage-inchina-is-the-us-next/?sh=6b8fad466535.

[2] CNNIC (2021) The 47th Statistical Report on Internet Development in China http://www.gov.cn/xinwen/202102/03/content_5584518.htm

[3] Zheng, Ruonan. "Livestream Goldmine: Kim Kardashian Meets Chinese Top Livestreamer
Viya." Jing Daily, 10 Nov. 2019, jingdaily.com/livesteam-goldmine-kim-

kardashian-meets-chinese-top-livestreamer-viya.

[4] "What Is Impulsive Buying? Definition of Impulsive Buying, Impulsive Buying Meaning." The Economic Times, 2020, economictimes.indiatimes.com/definition/impulsiv e-buying.

[5] Moura, Francisco Tigre. "Dopamine: More Than Pleasure, The Secret Is the Anticipation of a Reward.” LiveInnovation.Org, 2 Apr. 2020, liveinnovation.org/dopamine-more-than-pleasurethe-secret-is-the-anticipation-of-a-reward.

[6] Stern, Hawkins (1962). "The Significance of Impulse Buying Today". Journal of Marketing. 26 (2): 5962. doi:10.2307/1248439. ISSN 0022 2429. JSTOR 1248439.

[7] Mortimer, Gary. "The Decoy Effect: How You Are Influenced to Choose without Really Knowing It." The Conversation, 17 Feb. 2019, theconversation.com/the-decoy-effect-how-youare-influenced-to-choose-without-really-knowingit-111259.

[8] Eggspert, Today'S. "Limited Time Offer: How To Write a Discount Offer For Limited Time Only." The Daily Egg, 24 Mar. 2020, www.crazyegg.com/blog/limited-time-offers.

[9] "Scarcity Principle Definition.” Investopedia, 2019, www.investopedia.com/terms/s/scarcityprinciple.asp.

[10] Staff, Pon. "The Anchoring Effect and How It Can Impact Your Negotiation." PON - Program on Negotiation at Harvard Law School, 21 May 2020, www.pon.harvard.edu/daily/negotiation-skillsdaily/the-drawbacks-of-goals.

[11] Devenport, Jennifer. "The Effect of Authority and Social Influence on Eyewitness Suggestibility and Person Recognition." Journal of Police and Criminal Psychology, 1 Mar. 1996, link.springer.com/article/10.1007/BF02803685?err or=cookies_not_supported $\&$ code $=45316434-3360$ 47b8-b71b-2c110530a41d.

[12] Pettinger, Tejvan. "Sunk Costs.” Economics Help, 2019, www.economicshelp.org/blog/glossary/sunk-costs. 